\title{
Errores de asignación del acento en una niña hispanohablante con TEA: ¿retraso del lenguaje o un sintoma del trastorno autista?
}

\author{
Andrea Pereiro González \\ Universidad Abierta de Cataluña \\ Psicología y ciencias de la educación \\ c/Rambla del Poblenou, 156 \\ 08018 Barcelona \\ andre19.01.91@gmail.com
}

\author{
ANNA MARCZYK \\ Université Aix-Marseille \\ Laboratoire Parole et Langage \\ 5 av. Pasteur, \\ 13100 Aix-en-Provence \\ anna.marczyk@1pl-aix.fr
}

\begin{abstract}
ERRORES DE ASIGNACIÓN DEL ACENTO EN UNA NIÑA HISPANOHABLANTE CON TEA: ¿RETRASO DEL LENGUAJE O UN SÍNTOMA DEL TRASTORNO AUTISTA?
\end{abstract}

RESUMEN: Numerosos estudios han destacado las alteraciones de la prosodia afectiva y pragmática en los trastornos del espectro autista (TEA), pero son escasas las investigaciones que hayan estudiado las alteraciones de las formas más rudimentarias de la prosodia lingüística, como el acento. El objetivo de este estudio exploratorio es ofrecer un análisis preliminar de los errores de asignación del acento y de su realización fonética por una niña hispanohablante con rasgos del TEA desde un enfoque funciona, con el objetivo de determinar el origen de este déficit y atribuirlo al retraso del lenguaje o al trastorno autista.

PALABRAS CLAVES: acento léxico; trastorno del espectro autista; desplazamiento acentual; regularización del patrón acentual; español.

SUMARIO: 1. Introducción. 2 Método. 3. Resultados. 3.1. Identificación de los errores. 3.2. Análisis acústicos. 4. Discusión de los resultados. 5. Conclusiones.

\section{LEXICAL STRESS ASSIGNMENT ERRORS IN A SPANISH SPEAKING CHILD WITH ASD: LANGUAGE DELAY OR AUTISM SPECTRUM SYMPTOM?}

ABSTRACT: Numerous studies have highlighted the alterations of affective and pragmatic prosody in autistic spectrum disorder (ASD), but there are few studies concerned with alterations of more rudimentary forms of linguistic prosody, such as lexical stress. The objective of this exploratory work is to offer a preliminary functional analysis of lexical stress assignment errors and their phonetic realization by a Spanish-speaking girl with ASD in order to determine the origin of the deficit and attribute it to language development delay or autistic disorder.

KEY WORDS: lexical stress; autism spectrum disorder; stress displacement; regularization of lexical stress; Spanish.

SUMMARY: 1 . Introduction; 2. Method; 3. Results; 3.1. Error identification; 3.2. Acoustic analyses; 4. Discussion of the results; 5 . Conclusions.

\section{ERREURS \\ D'ASSIGNATION \\ D'ACCENT LEXICAL CHEZ UNE ENFANT HISPANOPHONE AVEC TSA: RETARD DE LANGAGE OU SYMPTOME DU TROUBLE DU SPECTRE DE L'AUTISME ?}

RÉSUMÉ: De nombreuses études ont mis en évidence les altérations de la prosodie affective et pragmatique dans les troubles du spectre de l'autisme (TSA), mais peu d'études se sont penchées sur les modifications des formes plus rudimentaires de la prosodie linguistique, telles que l'accent lexical. L'objectif de cette étude exploratoire est d'offrir une analyse préliminaire des erreurs d'attribution de l'accent et de sa réalisation phonétique par une fille hispanophone présentant les caractéristiques du TSA dans une perspective fonctionnelle, afin de déterminer l'origine de ce déficit et de l'attribuer au retard du langage ou à l'autisme.

MOTS CLÉS: accent lexical; trouble du spectre de l'autisme; déplacement accentuel régularisation de l'accent lexical; espagnol

SOMMAIRE: 1 . Introduction; 2 Méthode; 3. Résultats; 3.1. Identification des erreurs; 3.2. Analyses acoustiques; 4. Discussion des résultats; 5 . Conclusions.
Fecha de Recepción Fecha de Revisión Fecha de Aceptación Fecha de Publicación
$05 / 02 / 2019$

$26 / 02 / 2019$

$10 / 05 / 2019$

$01 / 12 / 2020$ 


\section{Errores de asignación del acento en una niña hispanohablante con TEA: ¿retraso del lenguaje o un sintoma del trastorno autista? 1}

ANDREa PEReiro GonZÁlez \& ANNA MARCZyK

\section{INTRODUCCIÓN}

El trastorno del espectro autista (TEA) y el trastorno en el desarrollo del lenguaje son dos cuadros clínicos a menudo susceptibles de confusión (Özyurt. y Eliküçük, 2018). En efecto, el retraso de las habilidades lingüísticas es uno de los primeros síntomas del autismo y una de las razones principales para remitir el niño a un psicólogo especializado (Thurm et al., 2007, Ellis et al., 2010). Sin embargo, hay factores que permiten disociar el déficit lingüístico debido al retraso en el desarrollo verbal del que acompaña el trastorno autista. Por ejemplo, si bien en el caso del retraso del lenguaje el problema suele resolverse espontáneamente o con la intervención logopédica temprana, el déficit lingüístico asociado con TEA es más estructural y su tratamiento puede requerir esfuerzos particulares. Además, dado que los orígenes patogénicos de estas dos entidades clinicas son diferentes, es legítimo pensar que pueda haber diferencias en los patrones del déficit lingüístico, pudiendo estas ser de orden cualitativo o cuantitativo. Por lo tanto, una mejor caracterización del déficit lingüístico en TEA parece oportuna y contribuiría a establecer el diagnóstico deferencial más fiable, así como a diseñar las intervenciones logopédicas más adecuadas. Este estudio se enmarca en esta línea de investigación y se propone documentar las alteraciones del acento léxico en una niña de TEA.

En la bibliografia sobre adquisición del lenguaje existe un consenso en considerar que la estructura prosódica, incluido el patrón acentual, se adquiere a edades relativamente tempranas (antes de los 4 años de edad, véase por ejemplo Gutiérrez, 2011; Gutiérrez y Palma, 2004; Kehoe, 1998), antes que la fonología segmental. Durante este periodo los errores son frecuentes y evidencian distintas etapas del proceso de adquisición. Por un lado, en una etapa temprana el niño aprende a ajustar los correlatos fonéticos del acento. Durante este periodo se observa una reducida contrastividad de las sílabas prominentes y las sílabas adyacentes, lo que produce la impresión de una acentuación monótona. En una etapa subsiguiente, en lenguas sin un patrón acentual predecible, se observan errores por cambio de acento con una pronunciada tendencia hacia el uso del patrón regular, debido a la sobregeneralización.

Respecto al déficit lingüístico en los niños con TEA, no obstante, la heterogeneidad de su conducta verbal, el déficit en el ámbito de la prosodia es

\footnotetext{
${ }^{1}$ Estudio financiado parcialmente por el proyecto COGNIPROS (FFI2013-40419-P) del Ministerio de Economia y Competitividad (España).
} 
uno de los rasgos más significativos que caracterizan esta población (Belinchón et al., 1992; Martos y Ayuda, 2002). Las alteraciones prosódicas en la producción del habla se manifiestan como anomalias que afectan a la prominencia y al contorno prosódico o a alguno de los parámetros acústicos constituyentes de las unidades suprasegmentales como el tono (frecuencia fundamental) o el volumen (intensidad). Debido a estas alteraciones, el habla de los niños con TEA produce en el interlocutor una impresión típica de "monotonía, arritmicidad, descontrol o inadecuación del volumen de la voz y falta de relación entre entonación y sentido" (Belinchón et al., 1992: 740). Un déficit de percepción del habla es a menudo concomitante al déficit de expresión y puede afectar tanto la función pragmática de la prosodia, como su función lingüística. Así, a nivel comunicativo, puede manifestarse en la incapacidad para identificar el foco oracional o para asociar el contorno entonativo con la intención comunicativa, y a nivel de la forma lingüística, en una falta de capacidad para percibir la diferencia de tono o de intensidad para distinguir entre dos unidades léxicas ${ }^{2}$. Aunque existen varios estudios sobre las alteraciones prosódicas, especialmente en lo que se refiere a la prosodia afectiva (véase la revisión reciente de McCann y Pepé, 2003), las alteraciones del acento léxico en TEA en el ámbito hispanófono no están documentados.

El acento puede definirse como un fenómeno fónico suprasegmental cuya función consiste en realzar la silaba prominente (tónica, fuerte) con respecto a las sílabas no prominentes (átonas, débiles, Gil, 2007). Se suele considerar que, en español, una lengua de acento libre, el patrón acentual de una unidad léxica (denominado acento léxico) forma parte de la representación léxicofonológica y puede recaer en cualquiera de las tres últimas silabas, incluyendo el componente flexivo (Alcoba, 2013), que forman esta unidad ${ }^{3}$. La gramática tradicional de la lengua española distingue tres patrones acentuales, determinados por la posición del acento en la unidad léxica:

(1) oxítono (agudo): café

(2) paroxitono (llano, grave): manzana

(3) proparoxítono (esdrújulo): boligrafo

En español el acento puede además cumplir una función distintiva, en términos de la escuela praguense (Trubetzkoy, 1949), o contrastiva, es decir, distingue unidades léxicas, por ejemplo, número "cantidad" y numeró "pretérito indefinido del verbo numerar" (véase por ejemplo Gil, 2007; Hualde, 2005). Respecto a la realización fonética del acento léxico, la prominencia se manifiesta acústicamente por medio de variaciones de duración, tono

\footnotetext{
${ }^{2}$ Retomamos el ejemplo citado en McCann y Pepé (2003: 333): la diferencia entre el verbo imprint (esp. imprimir) que lleva acento principal en la segunda sílaba y el sustantivo imprint (esp. marca) que lleva el acento en la primera sílaba.

${ }_{3}^{3}$ Denominada la Regla de Ventana de Tres Sílabas.
} 
(frecuencia fundamental, $f 0$ ) e intensidad (amplitud) que, en términos articulatorios, implican la acción de los pliegues vocales y de la musculatura relacionada con la respiración (Quilis, 1971 y 1981; Llisterri et al., 2005; Ortega, 2006).

En la bibliografia sobre adquisición del lenguaje existe un consenso en considerar que la estructura prosódica, incluido el patrón acentual, se adquiere a edades relativamente tempranas (antes de los 4 años de edad, véase por ejemplo Gutiérrez, 2011; Gutiérrez y Palma, 2004; Kehoe, 1998), antes que la fonología segmental. Durante este periodo los errores son frecuentes y evidencian distintas etapas del proceso de adquisición. Por un lado, en una etapa temprana el niño aprende a ajustar los correlatos fonéticos del acento. Durante este periodo se observa una reducida contrastividad de las sílabas prominentes y las sílabas adyacentes, lo que produce la impresión de una acentuación monótona. En una etapa subsiguiente, en lenguas sin un patrón acentual predecible, se observan errores por cambio de acento con una pronunciada tendencia hacía el uso del patrón regular, debido a la sobregeneralización.

Respecto al déficit lingüístico en los niños con TEA, no obstante, la heterogeneidad de su conducta verbal, el déficit en el ámbito de la prosodia es uno de los rasgos más significativos que caracterizan esta población (Belinchón et al., 1992; Martos y Ayuda, 2002). Las alteraciones prosódicas en la producción del habla se manifiestan como anomalías que afectan a la prominencia y al contorno prosódico o a alguno de los parámetros acústicos constituyentes de las unidades suprasegmentales como el tono (frecuencia fundamental) o el volumen (intensidad). Debido a estas alteraciones, el habla de los niños con TEA produce en el interlocutor una impresión típica de "monotonía, arritmicidad, descontrol o inadecuación del volumen de la voz y falta de relación entre entonación y sentido" (Belinchón et al., 1992: 740). Un déficit de percepción del habla es a menudo concomitante al déficit de expresión y puede afectar tanto la función pragmática de la prosodia, como su función lingüística. Así, a nivel comunicativo, puede manifestarse en la incapacidad para identificar el foco oracional o para asociar el contorno entonativo con la intención comunicativa, y a nivel de la forma lingüística, en una falta de capacidad para percibir la diferencia de tono o de intensidad que distingue entre dos unidades léxicas ${ }^{4}$.

Asimismo, este estudio exploratorio tiene como objetivo identificar si los errores de asignación del acento observados en el habla de una niña hispanohablante con rasgos del trastorno de espectro autista (TEA) y un retraso del lenguaje reflejan un mecanismo de regularización del patrón acentual o si, por el contrario, manifiestan una tendencia hacia un modelo irregular. En función de este resultado se determinará si estos errores deberían atribuirse a un retraso de lenguaje, de naturaleza más regular y evolutiva, o al trastorno

\footnotetext{
${ }^{4}$ Retomamos el ejemplo citado en McCann y Pepé (2003: 333): la diferencia entre el verbo imprint (esp. imprimir) que lleva acento principal en la segunda silaba y el sustantivo imprint (esp. marca) que lleva el acento en la primera sílaba.
} 
autista, caracterizado por su estructura más aleatoria e irregular. Los errores recogidos en las tareas de denominación de imágenes y de repetición permiten observar un desplazamiento acentual hacia la derecha, donde las palabras esdrújulas se vuelven llanas o agudas y las palabras llanas se vuelven agudas. Mientras que el primer tipo de errores sugiere un paso de la categoría marcada (esdrújula) a la no marcada (llana) y, por lo tanto, un proceso de regularización, el cambio acentual de la palabra llana o esdrújula a una palabra aguda - una categoría irregular, según el enfoque descriptivo tradicional de la prosodia acentual del español - no encaja con la hipótesis de regularización. Para alcanzar este objetivo examinaremos cómo su producción se ve influenciada por el patrón acentual y por la categoría morfológica de la palabra (sustantivo o verbo), con la hipótesis de que sus errores reflejan una tendencia hacia la regularización del patrón acentual, al igual que en el desarrollo lingüístico típico.

El segundo objetivo consiste en situar este déficit respecto al proceso de adquisición del acento durante el desarrollo. La percepción de un desplazamiento acentual sugiere que la participante domina la expresión fonética del acento y que la distintividad entre las sílabas tónicas y átonas está correctamente adquirida. Se comprobará esta hipótesis mediante un análisis acústico de los correlatos del acento en las producciones identificadas como correctamente acentuadas. Seguidamente, se analizarán las producciones con desplazamiento del acento para determinar qué parámetros contribuyen a la percepción de la prominencia. Si estos errores reflejan una etapa intermedia de la adquisición del habla, avanzamos la hipótesis de que su realización fonética sea subóptima, al no estar consolidada, en comparación con las producciones correctas.

\section{MÉTODO}

\subsection{Participante}

La participante en este estudio es una niña hispanohablante de 8 años de edad, diagnosticada a los 3.5 años con TEA y retraso del lenguaje por una psicóloga infantil. La niña es sujeto de una escolarización combinada y acude a un centro ordinario 3 días a la semana y el resto a un centro de Educación Especial. La evaluación mediante una batería de pruebas (PLONR,Aguinaga et al., 2005; Ela-R, García Pérez y Albor-Cohs, 1999) pone de manifiesto un retraso en todos los componentes del lenguaje: la articulación de los sonidos del habla (grupos consonánticos, fonemas / $\theta / \mathrm{y} / \mathrm{t} /$ ), así como alteraciones de entonación, ritmo y acento, falta de dominio de los 
pronombres personales que se refleja esencialmente en la inversión pronominal, es decir, sustitución del pronombre yo por tú o ella y deixis personal, problemas con las estructuras relativas y la negación, y a nivel pragmático, dificultades con la estructura del relato oral y un déficit leve de comprensión, predominantemente en enunciados complejos, implicaturas no convencionales o lenguaje figurativo. La niña tiene también dificultades con la psicomotricidad fina, presenta conductas repetitivas e intereses obsesivos. Antes de empezar la recogida de datos de la participante, la primera autora del estudio obtuvo el consentimiento informado de los padres de la niña.

\subsection{MATERIAL Y PROCEDIMIENTO}

Para la tarea de denominación se utilizaron pictogramas que representaban sustantivos con distinto patrón acentual (ej. café, manzana, boligrafo). La prueba constaba de un total de 36 pictogramas, 12 palabras para cada patrón acentual. Para el patrón oxítono y paroxítono se incluyeron palabras bisilábicas y trisilábicas (ej. león, corazón) con el fin de ver si el número de sílabas influía en la aparición de errores. Para la realización de los pictogramas se utilizó el programa en línea Pictotraductor (Disponible en: https://www.pictotraductor.com/). Los ítems fueron presentados a la participante de manera aleatoria.

Para ver si los errores de desplazamiento acentual dependian de la categoría morfológica de la palabra se utilizó una parte del protocolo Cognipros (Baqué et al., 2016), diseñado para evaluar el acento morfológico contrastivo (ceno, primera persona singular del presente de indicativo frente a cenó, tercera persona singular del pretérito indefinido). La tarea del protocolo consistió, en la primera condición, en completar la frase Yo cada día... basándose en las imágenes presentadas (véase un ejemplo en la Figura 1). Asimismo, en la primera condición se buscaba obtener un sintagma verbal de estructura verbo más complemento (ej. lavo la taza) en el tiempo verbal presente de indicativo. En la segunda condición, se pedía a la participante acabar la frase que requeria el tiempo verbal pretérito de indefinido: Aquel día, Sara... Antes de empezar la tarea, se comprobó que la participante entendía la tarea.

\footnotetext{
${ }^{5}$ Véase Belinchón et al. (1992: 736) para la descripción de este sintoma habitual del TEA en hispanohablantes.
} 


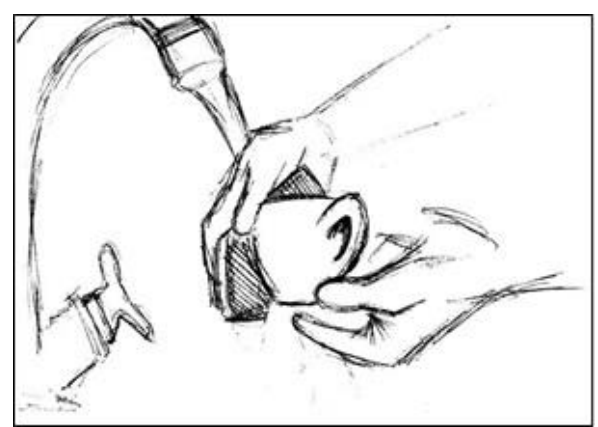

Figura 1: Ejemplo de pictograma para la tarea de denominación de acciones (protocolo Cognipros). Respuesta esperada: Yo cada día... $\rightarrow$ lavo la taza. Sara aquel día ... $\rightarrow$ lavó la taza.

En la segunda sesión de trabajo se pidió a la participante que repitiera todas las palabras de las pruebas de denominación de sustantivos y verbos. Las dos sesiones de grabación de los datos de audio tuvieron lugar en el domicilio de la participante.

El análisis acústico se llevó a cabo con el programa Praat, versión 6.0.43 (Boersma y Weenink, 2017). El corpus se transcribió ortográficamente, se segmentó de manera automática con el plug-in EasyAlign (Goldman, 2011). La segmentación se corrigió manualmente. Los parámetros de duración vocálica, frecuencia fundamental y amplitud (intensidad) de las vocales tónicas y átonas se extrajeron mediante un script de Praat. Los análisis estadísticos se realizaron mediante los modelos de regresión lineal con el programa R (R Development Core Team, 2013).

\section{Resultados}

\subsection{IDENTIFICACIÓN DE LOS ERRORES}

En las tareas experimentales se observaron 19 errores de desplazamiento acentual sobre un total de 60 palabras, con tendencia a regularizar el patrón acentual, es decir, los cambios se produjeron hacia un patrón paroxitono (ej. periódico - periodIco). Se observó también una tendencia, sobre todo en los verbos, hacia el patrón oxítono (ej. brócoli - brocolI, (yo) ceno - (yo) cenO). En los sustantivos con acento paroxitono se observaron 2 errores, todos por desplazamiento del acento a la sílaba adyacente la derecha. No se observaron errores en los sustantivos con patrón acentual oxitono. Respecto a la tarea, hubo significativamente más errores en la tarea de denominación (13 errores) que en la de repetición (6 errores). No hubo diferencias significativas entre el número de errores en los sustantivos (11 errores) y los verbos (8 errores). En la Tabla 1 se recogen todos los errores en función de la tarea y del tipo de error. 


\begin{tabular}{|c|c|c|c|c|}
\hline Tarea & $\begin{array}{l}\text { Proparoxitona } \rightarrow \\
\text { Paroxitona }\end{array}$ & $\begin{array}{l}\text { Proparoxí- } \\
\text { tona } \\
\rightarrow \text { Oxitona } \\
\end{array}$ & $\begin{array}{c}\text { Paroxitona } \rightarrow \\
\text { Oxitona }\end{array}$ & $\begin{array}{l}\text { Oxitona } \rightarrow \\
\text { Paroxitona }\end{array}$ \\
\hline $\begin{array}{l}\text { Denomina- } \\
\text { ción de } \\
\text { imágenes }\end{array}$ & $\begin{array}{c}\text { triángulo } \rightarrow \text { triangUlo } \\
\text { periódico } \rightarrow \text { periodIco } \\
\text { cáscara } \rightarrow \text { cascAra } \\
\text { rectángulo } \rightarrow \text { rectan- } \\
\text { gUlo brújula } \rightarrow \text { bru- } \\
\text { jUla }\end{array}$ & $\begin{array}{l}\text { brócoli } \rightarrow \\
\quad \text { brocolI }\end{array}$ & $\begin{array}{c}\text { manzana } \rightarrow \text { man- } \\
\text { zanA } \\
\text { cárcel } \rightarrow \text { carcEl }\end{array}$ & \\
\hline $\begin{array}{c}\text { Repetición } \\
\text { de palabras } \\
\text { aisladas } \\
\end{array}$ & $\begin{array}{c}\text { triángulo } \rightarrow \text { triangUlo } \\
\text { rectángulo } \rightarrow \text { rectan- } \\
\text { gUlo }\end{array}$ & & $\begin{array}{c}\text { manzana } \rightarrow \text { man- } \\
\operatorname{zan} A\end{array}$ & \\
\hline $\begin{array}{l}\text { Cognipros: } \\
\text { denomina- } \\
\text { ción de } \\
\text { imágenes } \\
\end{array}$ & & & $\begin{array}{c}\text { fumo } \rightarrow \text { fumO } \\
\text { saco } \rightarrow \text { sacO ceno } \\
\rightarrow \text { cenO lavo } \rightarrow \\
\text { llevO miro } \rightarrow \text { miro }\end{array}$ & \\
\hline $\begin{array}{l}\text { Cognipros: } \\
\text { repetición }\end{array}$ & & & $\begin{array}{l}\text { saco } \rightarrow \text { sacO } \\
\text { ceno } \rightarrow \text { cenO }\end{array}$ & $\begin{array}{c}\text { dejó } \rightarrow \\
\text { dEjo }\end{array}$ \\
\hline
\end{tabular}

Tabla 1. Errores de asignación de acento en función de la tarea y del patrón acentual

\subsection{ANÁlISIS ACÚSTICOS}

\subsubsection{DENOMINACIÓN DE IMÁGENES}

A continuación, se presentan los resultados del análisis de los correlatos acústicos del acento en función de la identificación de estas realizaciones como correctas o con desplazamiento acentual. Estos análisis se limitan a la tarea de denominación, donde se observaron más errores respecto a la de repetición.

De manera general, las vocales tónicas y átonas en palabras identificadas como correctas se distinguen en el plano fonético mediante la acción de tres correlatos fonéticos: la duración, la frecuencia fundamental y la intensidad. Las vocales tónicas identificadas como correctas son más largas que las átonas $(t(79)=3.50, \mathrm{p}=0.004, \mathrm{M}=165 \mathrm{~ms}(8)$ frente a $\mathrm{M}=128 \mathrm{~ms}(6))$, presentan los valores medios de la $f 0$ superiores a los de las sílabas no acentuadas $(t(69)=2.90, \mathrm{p}=0.025, \mathrm{M}=208 \mathrm{~Hz}(10)$ frente a $\mathrm{M}=170 \mathrm{~Hz}(8)), \mathrm{y}$ se caracterizan por una mayor intensidad $(t(79)=4.17, \mathrm{p}=0.000, \mathrm{M}=64$ $\mathrm{dB}(1.17)$ frente a $\mathrm{M}=58 \mathrm{~dB}(0.87))$. Además, respecto a la duración vocálica se aprecia un efecto del patrón acentual $(t(2)=4.54, p=.022)$. La contribución de la duración vocálica es mayor en las palabras oxitonas (ej. café, M $=192 \mathrm{~ms}$ (13)) que proparoxitonas (ej. número, $\mathrm{M}=131 \mathrm{~ms}$ (15)). Tal efecto no llega a ser significativo para la $f 0(\mathrm{p}=.090)$ y la intensidad $(\mathrm{p}=.751)$, cuyos valores medios en sílabas tónicas son comparables independientemente de la posición en la palabra.

Los análisis de los correlatos fonéticos del acento en los casos de desplazamiento acentual, tanto cuando la vocal pasó de ser tónica a átona como 
en las átonas que llegaron a ser tónicas, sugieren que los errores forman una categoria intermedia entre las categorías "tónica" y "átona".

La media de la duración vocálica en las vocales tónicas por desplazamiento acentual no es significativamente diferente de la media de las vocales tónicas correctas $(\mathrm{t}(79)=0.18, \mathrm{p}=.997) \mathrm{ni}$ de las vocales átonas correctas $(t(79)=1.81, \mathrm{p}=.274)$. Se aprecia el mismo resultado para las vocales átonas por desplazamiento acentual, que no se distinguen en términos de la duración vocálica de la tónicas $(t(79)=0.20, \mathrm{p}=.997)$ ni de las átonas correctas $(t(79)=2.11, \mathrm{p}=.159)$.

El resultado de las $f 0$ es similar al de la duración vocálica. No se observan diferencias significativas entre las vocales tónicas por desplazamiento acentual y tónicas correctas $(t(69)=0.76, \mathrm{p}=.870)$, pero tampoco entre estas y las átonas correctas $(t(69)=2.51, \mathrm{p}=.067)$. Del mismo modo, no se observan diferencias entre las átonas por cambio del acento y las átonas correctas $(t(69)=0.015, \mathrm{p}=.999)$, ni tampoco entre los errores y las tónicas correctas $(t(60)=1.52, \mathrm{p}=.428)$.

Los análisis de la intensidad en los errores por cambio de acento ponen de manifiesto el mismo resultado. No existen diferencias significativas entre los errores - tanto las átonas como las tónicas por cambio del acento - y las mismas categorias identificadas como correctas (tónica por cambio del acento frente a tónicas correctas $t(79)=0.49, \mathrm{p}=.961$ ) y átonas correctas $(t(79)=1.87, \mathrm{p}=.248$; átona por cambio de acento frente a átonas correctas $t(79)=1.75, \mathrm{p}=.302$ y tónicas correctas $t(70)=0.60, \mathrm{p}=.932)$.

El conjunto de los resultados para las producciones correctas (en gris) y con cambio acentual (en blanco) se pueden apreciar en la Figura 2.
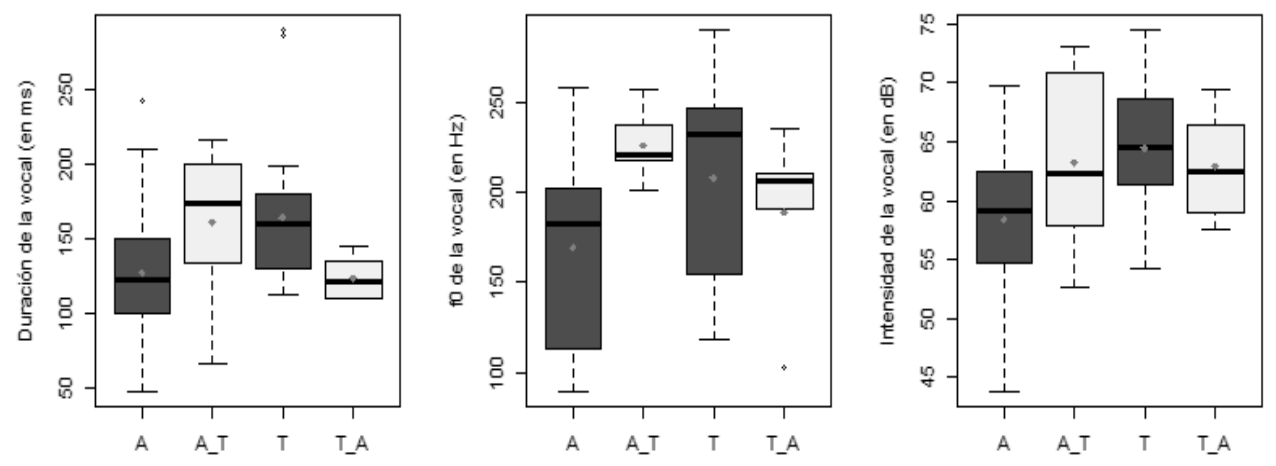

Figura 2: Distribución de los valores de los correlatos acústicos de la vocal tónica y átona (duración vocálica, fo e intensidad), obtenidos en la tarea de denominación de imágenes, en función de la categoría acentual $\left(\mathrm{A}\right.$ = átonas; $\mathrm{T}$ = tónicas; $\mathrm{A} \_\mathrm{T}$ = tónica por desplazamiento acentual; T_A = átona por desplazamiento acentual). La barra horizontal negra representa la mediana y el diamante la media. 


\subsubsection{Resultados de la PRUEba Cognipros}

Conviene recordar que en las tareas pertenecientes al protocolo Cognipros se observaron dos direcciones de cambio acentual: del patrón paroxítono al oxítono (ej. (уо) ceno - cenO) y del patrón oxítono al paroxítono (ej. dejó $d E j o)$. En estas tareas, el cambio de patrón acentual conlleva un error de morfología verbal (cambio de persona y tiempo verbal).

Los análisis de las producciones correctas ponen de manifiesto un efecto de la categoría acentual (sílaba tónica o átona) sobre todos los correlatos acústicos, al igual que en la tarea de repetición descrita del apartado anterior. Las sílabas tónicas son significativamente más largas que las átonas $(t(135)=7.49, \mathrm{p}=.000, \mathrm{M}=179 \mathrm{~ms}(5.5)$ frente a $\mathrm{M}=126 \mathrm{~ms}(4.5))$, tiene la $f 0$ significativamente superior $(t(113)=3.31, \mathrm{p}=.007, \mathrm{M}=195 \mathrm{~Hz}(6,1)$ frente a $167 \mathrm{~Hz}(5,8))$ asi como una intensidad superior $(t(135)=5.18, \mathrm{M}=64 \mathrm{~dB}$ (0.97) frente a $\mathrm{M}=58 \mathrm{~dB}(0.79))$.

Respecto a los errores acentuales, las vocales tónicas por desplazamiento del acento son significativamente más largas que las tónicas correctas, presentando una diferencia de $64 \mathrm{~ms}$ entre las medias de las dos categorias $(t(135)=4.55, \mathrm{p}=.000, \mathrm{M}=243 \mathrm{~ms}(13)$ frente a $126 \mathrm{~ms}(4.5))$. Este resultado sugiere que los errores no pertenecen a la categoria "sílabas tónicas" sino que forman una categoria aparte. Las sílabas átonas por desplazamiento acentual no se distinguen de las átonas correctas $(\mathrm{p}=.969)$ pero sí se distinguen de las tónicas $(t(135)=2.97, \mathrm{p}=.018)$.

El resultado de la $f 0$ muestra que tanto las vocales tónicas como las átonas por cambio acentual no difieren de las categorias correctas. Asimismo, las vocales tónicas no se distinguen de las tónicas correctas $(\mathrm{p}=.996)$ pero tampoco son diferentes de las átonas correctas $(\mathrm{p}=.389)$. Las vocales átonas por cambio acentual no difieren de las átonas correctas $(\mathrm{p}=.831)$ pero tampoco difieren de las tónicas correctas $(\mathrm{p}=.907)$.

Los resultados de la intensidad van en el mismo sentido para las vocales átonas por desplazamiento acentual pero no para las vocales tónicas. Las vocales átonas no se distinguen en términos de la intensidad ni de las átonas correctas $(\mathrm{p}=.863)$ ni de las tónicas correctas $(\mathrm{p}=.384)$. Respecto a las tónicas por desplazamiento acentual, estas producciones pertenecen a la misma categoria que las tónicas correctas, como demuestra la falta de diferencias significativas entre estas dos categorias $(t(135)=1.05, p=.719)$, una diferencia significativa entre esta categoría y las átonas correctas $(t(135)=3.78$, $\mathrm{p}=.013)$.

La distribución de los valores para todos los parámetros acústicos en función de la categoría acentual en las producciones correctas y en los errores está ilustrada en la Figura 3. 

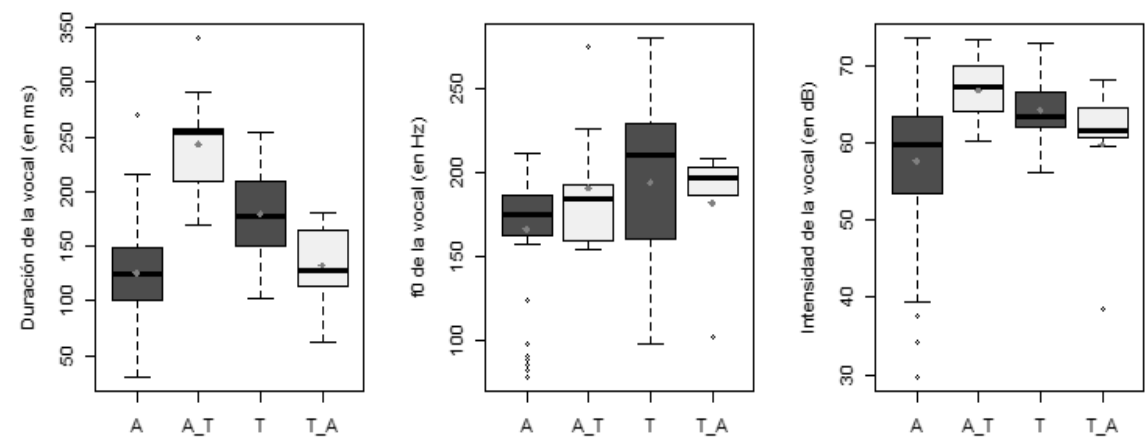

Figura 3: Distribución de los valores de los correlatos acústicos de la vocal tónica y átona (duración vocálica, $f 0$ e intensidad), obtenidos en las tareas del protocolo Cognipros, en función de la categoría acentual (A = átonas; $\mathrm{T}$ = tónicas; A_T = tónica por desplazamiento acentual; T_A = átona por desplazamiento acentual). La barra horizontal negra representa la mediana y el diamante la media.

\section{Discusión de los RESUltados}

En este estudio hemos examinado los patrones de desplazamiento acentual en el habla de una niña con TEA con el fin de determinar el origen de su déficit de asignación acentual respecto a su perfil clínico y al retraso del lenguaje que manifiesta. Avanzamos la hipótesis de que el retraso de adquisición del lenguaje se manifestaria, igual que en un desarrollo tipico, por una sobregeneralización del patrón acentual más común. Para evaluar si las observaciones confirman esta hipótesis, es necesario establecer primero qué patrón se considera como regular. En español se considera habitualmente el patrón paroxítono como categoría no marcada ${ }^{6}$. Los resultados muestran, efectivamente, una tendencia significativa a regularizar el patrón proparoxítono al paroxítono, lo que va en el sentido de nuestra hipótesis. Sin embargo, para los sustantivos y adjetivos acabados en consonante, el acento no marcado recae en la sílaba oxítona (ej. albañil, perfil) aunque las excepciones son frecuentes (ej. lápiz, cárcel). Uno de los errores de la hablante pertenece a esta categoria (cárcel - carcEl), por lo tanto lo consideramos como perteneciente a la categoría de errores por regularización del acento. Otro caso parecido se da en el error brócoli - brocoll. Las palabras del español acabadas en 'i' que no sean abreviaciones (ej. bici, uni, etc.) son frecuentemente acentuadas en la última sílaba (ej. jabali, aquí...), por lo tanto, se puede pensar que la locutora tiene más dificultad con estas unidades. Finalmente, algunos errores no se explican con el modelo de regularización, como manzana - manzanA (error tanto en denominación como en repetición). Es posible que este tipo de errores, mucho menos frecuentes, se deban a una alteración de

\footnotetext{
${ }^{6}$ 95\% del léxico en español según Hualde, 2005.
} 
prosodia característica del autismo, que presenta una estructura menos regular que un retraso de lenguaje.

Por otro lado, los datos de producción de la hablante no permiten excluir una hipótesis alternativa, según la cual los errores no se analizarian respecto a la dimensión Regular/Irregular. Según esta hipótesis, la hablante siempre desplazaría el acento a la sílaba adyacente a la derecha, y las consecuencias de este desplazamiento (tendencia hacia un paradigma regular o irregular) serían aleatorias. Refutar esta hipótesis necesitaría una investigación más controlada, con un protocolo más extenso.

Respecto a los errores en los verbos, observamos una tendencia muy pronunciada a realzar la sílaba oxítona, lo que conlleva un error gramatical asociado a la flexión verbal (tiempo y persona). Es sabido que, en el caso de los verbos, la vocal final no es neutral respecto al acento y lleva la información gramatical contrastiva. Mientras que la asignación del acento en los sustantivos en singular posiblemente ocurre durante la codificación léxica, es legítimo pensar que la asignación del acento morfológico se computa - dado que es predecible en la mayoría de los casos - durante una etapa posterior. En este sentido, el paradigma que utilizamos para el análisis de los sustantivos (Regular/Irregular) no parece válido para el análisis de los errores en los verbos y sería incorrecto concluir que la hablante muestra una tendencia a usar la forma marcada al confundir cEno con cenO. Cabe recalcar que la hablante nunca comete errores de asignación del acento en el complemento del verbo, que corresponde en todos los casos a una palabra bisilábica acentuada en la penúltima sílaba (bici, cena, sopa, pipa, taza). Es más probable, por lo tanto, que ella tenga un déficit que afecta la computación de la flexión verbal que en español se manifiesta necesariamente a través del acento. Este error puede deberse a la dificultad de la niña, evocada anteriormente, con el uso de los pronombres (tú, yo, ella) que es característica del autismo (véase $\S$ Participante). Por lo tanto, parece que los errores de desplazamiento acentual en las formas verbales están más bien influidos por el trastorno autista que por un retraso del lenguaje.

Respecto a los análisis acústicos de las producciones correctas y de los errores, se desprende de ellos que la hablante ha superado la etapa de adquisición de la manifestación fonética del acento. En efecto, las producciones correctas ponen de manifiesto que la hablante usa todos los parámetros fonéticos (tono, duración e intensidad) para marcar la diferencia entre sílabas tónicas y átonas. En cuanto a los errores, estos parecen formar, en la mayoría de los casos, una categoría intermedia entre las vocales correctamente acentuadas y las no acentuadas. Por lo tanto, el conjunto de los resultados sugiere que no se trata aquí de un error fonológico/léxico consolidado, sino más bien de las producciones intermedias y en evolución, lo que iría en el sentido de un retraso de lenguaje. 


\section{Conclusiones}

Los análisis de los factores que inciden en la aparición de los errores de desplazamiento acentual, presentados en este estudio exploratorio, van en el sentido de la existencia de distintos niveles de codificación del acento en la producción verbal, que podrían ser objeto de un déficit específico del TEA. La presencia de la tendencia manifiesta hacia el patrón acentual no marcado, en función de la categoría morfológica de la palabra, y la realización fonética poco consolidada de la prominencia acentual permiten situar los errores observados fundamentalmente como una manifestación del retraso del lenguaje.

\section{REFERENCIAS}

AGUINAGA AYERRA, G. et al. (2005): PLON-R: Prueba de Lenguaje Oral Navarra-Revisada: manual (2a edic.), Madrid: TEA Ediciones.

ALCOBA, S. (2013): "Cambios de acento en español", Verba, 40, pp. 415-52.

BAQUÉ, L. et al. (2016): Corpus del proyecto Cognipros. Documento técnico no publicado.

BELINCHÓN, M. et al. (1992): "Las alteraciones del lenguaje desde la perspectiva psicolingüística", Psicología del lenguaje, Valladolid: Trotta.

BOERSMA, P. \& WEENINK, D. (2017): Praat: doing phonetics by computer. Disponible en: http://www.praat.org/ (Fecha de consulta: 01/11/2018).

ELLIS S. et al. (2010): "Early language patterns of toddlers on the autism spectrum compared to toddlers with developmental delay", Journal of autism and developmental disorders, 40 (10), pp. 1259-1273.

GARCÍA PÉREZ, M. y ALBOR-COHS, G. (1999): Ela-R, Examen logopédico de articulación revisado. Madrid: Cruces-Barakaldo Cohs.

GARRIDO, J. M. et al. (1993): "Prosodic differences in reading style: Isolated vs. Contextualized Sentences", Actas de Eurospeech: European Conference on Speech Communication and Technology, Berlin: 21-23 September 1993, vol 1. pp. 573576.

GIL, J. (2007): Fonética para profesores de español: De la teoría a la práctica, Madrid: Arco/Libros.

GOLDMAN, J.-P. (2011): "EasyAlign: a quasi-automatic phonetic alignment tool under Praat", Actas del congreso InterSpeech (Septiembre 2011, Firenze, Italia).

GUTIÉRREZ PALMA, N. (2011): "Procesamiento silábico y acento en español", Revista de Logopedia, Foniatría y Audiología, 31 (1), pp. 1-43.

GUTIÉRREZ PALMA, N. y PALMA REYES, A. (2004): "Acento léxico y lectura: un estudio con niños", Revista Electrónica de Investigación Psicoeducativa y Psicopedagógica, 2 (2), pp. 143-160.

HUALDE, J. I. (2005): The Sounds of Spanish, Cambridge: Cambridge University Press.

KEHOE, M. (1998): "Support for metrical stress theory in stress acquisition", Clinical Linguistics \& Phonetics, 12 (1), pp. 1-23.

LLISTERRI BOIX, J. et al. (2005): "La percepción del acento léxico en 
español", Filología y Lingüística, 1, pp. 271-297.

MARTOS, J. y AYUDA, R. (2002): “Comunicación y lenguaje en el espectro autista: el autismo y la disfasia", Revista de Neurología, 34 (1), pp. 58-63.

MCCANN, J. \& PEPPÉ, S. (2003): "Prosody in autism spectrum disorders: a critical review", International Journal of Language \& Communication Disorders, 38, pp. 325-350.

ORTEGA LLEBARIA, M. (2006): "Phonetic cues to stress and accent in Spanish", Díaz Campos, M. (ed.): Selected Proceedings of the 2nd Conference on Laboratory Approaches toSpanish Phonetics and Phonology. Somerville, MA: Cascadilla Proceedings Project. pp. 104-118.

ÖZYURT, G. \& ELIKÜÇÜK, Ç. D. (2018): "Comparison of Language Features, Autism Spectrum Symptoms in Children Diagnosed with Autism Spectrum Disorder, Developmental Lan- guage Delay, and Healthy Controls", Archives of neuropsychiatry, 55 (3), pp. 205-210.

QUILIS, A. (1971): "Caracterización fonética del acento español", Travaux de Linguistique et de Littérature, 9 , pp. 53-72.

QUILIS, A. (1981): Fonética acústica de la lengua española, Madrid: Gredos.

$\mathrm{R}$ DEVELOPMENT CORE TEAM. (2013): R Development Core Team. R: A Language and Environment for Statistical Computing, Vienna: R Foundation for Statistical Computing. Disponible en: http://www.r-project.org/ (Fecha de consulta: $01 / 05 / 2018)$.

THURM, A. et al. (2007): "Predictors of language acquisition in preschool children with autism spectrum disorders", Journal of Autism and Developmental Disorders, 37, pp. 1721-1734.

TRUBETZKOY, N. S. (1949): Principes de phonologie, Paris: Klincksieck. 